\title{
Wasted World: How Our Consumption Challenges the Planet
}

\author{
by Rob Hengeveld \\ Chicago: University of Chicago Press 2012 \\ ISBN 978-0-22632-699-3 \\ Hardcover, \$30, 335 pp. \\ Reviewed by Don Kerr \\ Department of Sociology, King's University College at Western (London, ON)
}

\begin{abstract}
Demographers are all too familiar with "neo-Malthusian" arguments relating to overpopulation. While many environmental and social scientists appreciate the importance and relevance of human population (its size and growth) to environmental impact, it is really a question of emphasis. The neo-Malthusian argument is unequivocal in this regard. As Hengeveld writes in his introduction: "This book is about problems principally arising from too many people living on earth" (p. iv). The population biologist Paul Erhlich made essentially this same case in the 1970s, arguing that the world already had a population beyond its carrying capacity and that a dramatic reduction in fertility was immediately necessary to avoid economic and ecological collapse. Yet the simple fact was that the worst of Ehrlich's fears were exaggerated, fertility has since decline substantially, and his book The Population Bomb (1970) was widely criticized as being non-scientific. Regardless, this has not kept Rob Hengeveld from presenting virtually the same argument in this book.

Hengeveld is affiliated with the Centre for Ecosystem Studies in Wageningen, Netherlands. Not surprisingly, given the disastrous loss of biodiversity that has characterized the modern era, there is a deep pessimism in this book. Briefly, Hengeveld's forecasts are rather apocalyptic, with human mortality and environmental collapse considered to be inevitable unless dramatic measures are taken immediately to reduce population. To this biogeographer, what has happened to other species will quite likely happen to us unless dramatic action is taken. His book is concerned with three key problems: (i) unsustainable population growth, (ii) overconsumption, and (iii) the resultant accumulated waste which is produced, much beyond the capacity of natural systems to absorb. As the Earth's resources are limited and we seem to be inevitably producing and accumulating far too much waste, dramatic measures are called for.

For Hengeveld, the underlying factor driving the ecological damage has been human population growth. All life requires both mineral resources and energy, but the scale of this dependency is qualitatively and quantitatively different with human populations. Our reliance on exploiting mineral resources and energy has grown exponentially with population growth. Human beings first obtained the energy they required from food, but as populations grew larger and more complex; the demand for resources and energy grew. Due to demographic growth and greater population densities, we eventually moved to other energy sources, first animal and wind, and then, more recently, fossil fuels, and nuclear, among others. The resultant waste from our consumption and energy use is typically not obvious, as we store massive amounts out of site in landfills, while atmospheric wastes and greenhouse gases quickly dissipate into the atmosphere. But what of the longer term consequences, as we live in a world that is increasingly drowning in its waste? The argument seems compelling, somewhat sobering, and perhaps all too familiar.

Despite the importance of Hengeveld's work, unfortunately there are some major problems from the point of view of a demographer. Given his neo-Malthusian emphasis, he asks the fundamental question: "if we are to reduce our numbers, by how much should we do so?" His solution is dramatic, "to go back to roughly $1 / 7$ th
\end{abstract}


of our current population" (p. 200), or in other words, roughly 1 billion. While no timeframe is provided here, contrast this with the UN's long-term, medium-growth projection of 10.1 billion by 2100 , which assumes quite reasonably that global fertility might converge toward the replacement level over the next half-century or so. By any reasonable accounting, then, what Hengeveld proposes is dramatic. Moreover, while the informed social scientist might ask "how one gets there from here?" the details are certainly not forthcoming in this book.

Hengeveld's background is in ecology and not in demography. With this in mind, his book makes some rather fundamental errors, which leaves the reader somewhat concerned. For example, as he writes, "In the 1970s, the human population numbered roughly 2.5 billion. Now, only 35 years later, it is just over 7 billion" (p. 6). In reality, the UN estimates that the global population was 2.5 billion back in the mid-1950s, not the 1970s. Later, he writes, "during the 1970s, we were warned explicitly at a time when we still had the chance to find reasonably easy solutions, but since then the world population has almost tripled" (p. 70). As to what he means by "reasonably easy solutions" back in the 1970s, the reader is left scratching his head, not to mention the fact that global population has doubled since 1970 and not tripled. He also writes, "that's an average increase of some 1.3 billion people every decade, which means that each year there are an extra 130 million humans to be fed, housed, and clothed" (p. 7). A simple reality check with the UN Population Division again leads to credibility issues: population growth peaked at roughly 88 million annually during the 1990s, rather than 130 million, and no decade has seen more than 0.9 billion added to global population, not 1.3 billion. Where Hengeveld came up with his numbers is a mystery, as typically no referencing is provided within this text, and little scientific literature is cited.

While such a critique might be considered nitpicky, my fundamental point is this: to a demographer who hopes to scientifically and carefully chart the impact of population growth on the environment, this text is empirically quite sloppy. Hengeveld, who emphasizes "population" as the root cause of our problems, might at least get his numbers straight. From this point on, the reader cannot help but doubt the author's credibility. This is particularly disturbing as the reader moves into areas that the discipline of demography is less familiar with, as for example, the ecological literature on resource utilization, energy use, and waste production. This appears to be the strength of the book, from the perspective of a biologist whose expertise is in the abundances and distribution of species. Indeed, this is where ecologists have made several important contributions to the debate on sustainability and population growth, raising issues that demographers, economists, and other social scientists should pay attention to but far too often ignore.

What is certain is that living systems produce waste as part of a cycle, whether we speak of human beings or bacteria. Hengeveld emphasizes that this waste can be absorbed, processed, or recycled, yet never completely. Over the longer term, there are clearly limits to this process. The earth is largely a closed system, with the exception of the energy that we receive from the sun. In this context, Hengeveld is interested in how we might move to a more cyclical system of resource utilization and waste production rather than the current linear systemwhich often produces a toxic environment, hazardous to both human life and the planet's biodiversity. Hengeveld's book is most interesting in his description of how human populations have created economic systems that involve a linear system of resource use and waste production, one which is leading to excessive amount of accumulated waste.

Yet the deep pessimism in this book rests with the deterministic idea that human population growth, in and of itself, is the primarily factor responsible for this destruction, and that this dynamic between human numbers and the environment is largely beyond our control. The social sciences have highlighted other factors_or, most fundamentally, cultural, economic, political, and technological issues - that are particularly important in this context. Many would argue that these factors are far more important than mere population size in this regard. There is obviously potential for economic models that allow for greater sustainability, distinct from the current emphasis on economic growth and the resultant waste. However, given the real political difficulties that we will likely encounter in "getting there from here," perhaps many others might share Hengeveld's pessimism. 